Textures and Microstructures, 1987, Vol. 7, pp. 11-28

Photocopying permitted by license only

(C) Gordon and Breach Science Publishers Inc., 1987

Printed in the United Kingdom

\title{
The Effect of Carbon Content on Recrystallisation and Texture Development in Steel
}

\author{
K. USHIODA, $\dagger$ U. v. SCHLIPPENBACH $\S$ and W. B. \\ HUTCHINSON $\dagger$
}

\author{
$\dagger$ Swedish Institute for Metals Research Stockholm, Sweden \\ §Institut für Allgemeine Metallkunde und Metallphysik, RWTH, FRG
}

(Received 28 May 1986)

The effect of differential carbon contents on recrystallisation and texture development has been studied using samples designed to have a known concentration profile. Dissolved carbon can play an active role both at the deformation and annealing stages. Textural changes are associated principally with enhancement of the nucleation rate for recrystallisation with increasing carbon contents. The $\{111\}$ components become weaker and are replaced by widely scattered orientations. Interstitial carbon present during rolling gives rise to shear banding, causing a further increase in nucleation rate during recrystallisation and an associated development of the Goss texture.

\section{INTRODUCTION}

It is well documented that annealing textures in steel are strongly influenced by the presence of foreign atoms such as carbon, nitrogen and sulfur (e.g. Ref. 1). The generally deleterious effect of these elements can be alleviated by the addition of carefully controlled amounts of elements such as titanium, aluminium and manganese which have a scavenging effect on the impurities. ${ }^{2}$ This scavenging action provides a purer matrix which results in an

\footnotetext{
$\ddagger$ Now at R \& D Laboratories II, Nippon Steel Corp, Japan.
} 
increase in strength of the $\{111\}$ annealing texture and improved deep drawability of the sheet product. Recognition of the deleterious effect of carbon, especially in continuous annealing processes, has lead to significant reduction in the content of this element in commercial steels with levels as low as $0.003 \%$ being produced in some cases. ${ }^{3}$

The mechanism(s) by which foreign atoms affect annealing textures is complex and poorly understood even in a rather simple system such as $\mathrm{Fe}-\mathrm{MnC}$. $\mathrm{Hu}$ and Goodman ${ }^{4}$ showed clearly that decreased manganese contents generally increase the $\bar{r}$-value of cold rolled and annealed steel except at very low levels where the $\bar{r}$-value decreases abruptly. Results of Hughes and Page ${ }^{5}$ suggest an interaction between manganese and carbon in that they demonstrate an optimum steel composition with respect to the contents of these elements. The above results were obtained for slow heating conditions as in batch annealing. For conditions of rapid continuous annealing it has been shown that texture development is critically dependent on interactions between carbon and manganese atoms present in solid solution. . $^{6,7}$

According to Leslie et al. ${ }^{8}$ who studied the kinetics of recrystallisation in Fe-Mn binary alloys, manganese decreases the rate of growth of recrystallising grains due to a solute drag effect. The interstitial elements carbon and nitrogen have virtually no effect on the recrystallisation kinetics in pure iron according to Venturello et $a l .{ }^{9,10}$ These workers reported a retardation of recovery in the presence of interstitials but the results should be viewed with some caution since they were based on hardness measurements and were probably influenced by dislocation locking effects.

Despite the fact that annealing textures develop as a result of the nucleation and growth of recrystallised grains, there have been few attempts to analyse the texture development in terms of the kinetics of the transformation. The present paper aims at a better understanding of the effect of carbon in steel by combining texture measurements with quantitative metallographic examination of the progress of recrystallisation. Recent work $^{11,12}$ has shown that carbon in solid solution can influence the final texture through effects on both the cold rolling (deformation) and annealing (recrystallisation) stages of processing. These two situations have 
been distinguished in the present work by controlling the state of carbon/carbide dispersion in the steel.

\section{EXPERIMENTAL}

A special type of specimen was developed to permit investigation of a range of different carbon contents while all other parameters were held constant. This was achieved by creating a known carbon gradient through the thickness of the plate in the initial condition so that any desired carbon level could be examined by simply sectioning the sheet at the appropriate depth. A commercial steel hot band $(0.047 \% \mathrm{C}, 0.01 \% \mathrm{Si}, 0.23 \% \mathrm{Mn}, 0.006 \% \mathrm{P}, 0.007 \% \mathrm{~S}$, $0.050 \% \mathrm{Al}$ and $0.0049 \% \mathrm{~N}$ ) of initial thickness $3.6 \mathrm{~mm}$ was subjected to the following treatments.

i) normalised $930^{\circ} \mathrm{C} / 20$ minutes to achieve a stable grain structure in which the nitrogen was fully precipitated as AlN particles.

ii) reduced to $2.4 \mathrm{~mm}$ thick by grinding from both surfaces

iii) decarburisation $700^{\circ} \mathrm{C} / 1$ week in wet hydrogen

iv) decarburisation $700^{\circ} \mathrm{C} / 1$ week in dry hydrogen

v) removal of $0.1 \mathrm{~mm}$ from surfaces by chemical polishing

vi) partial carburisation $700^{\circ} \mathrm{C} / 10$ minutes in hydrogen gas saturated with methanol vapour.

vii) anneal $700^{\circ} \mathrm{C} / 2$ minutes in salt bath followed immediately by

viii) either water quenching (WQ) or rapid cooling to $500^{\circ} \mathrm{C}$ and then furnace cooling to room temperature (FC).

The partial carburisation during states (vi) and (vii) was designed to give a gradient in carbon content from $169 \mathrm{ppm}$ at the surface to $5 \mathrm{ppm}$ (unchanged) at the centre. Figure 1 shows the calculated carbon content as a function of depth in the plate using diffusion theory together with measurements using activation analysis ${ }^{13}$ at six different depths. Similar profiles are seen in the two cases although the measured values are consistently a little higher than those calculated. Specimen WQ was designed to retain all carbon in solid solution while treatment FC permitted precipitation of very small 
14 K. USHIODA, U. v. SCHLIPPENBACH AND W. B. HUTCHINSON

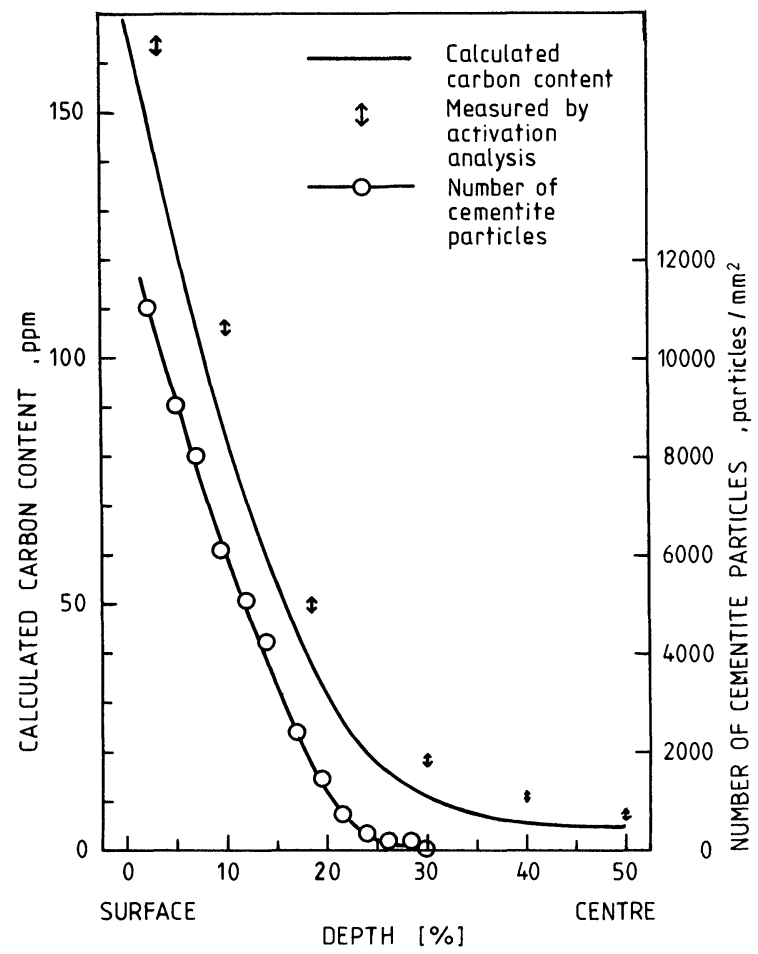

FIGURE 1 Calculated and measured carbon concentration profiles through thickness of the sheet together with the area density of carbide particles in sample FC.

cementite particles in the grain boundaries which dissolved during annealing after cold rolling. The area density of these cementite particles, also shown in Figure 1, decreased with total carbon content down to a level of approximately $15 \mathrm{ppm}$. Below this value no particles were visible presumably due to insufficient driving force for nucleation so it may be inferred that the carbon was then in solid solution irrespective of treatment (FC or WQ).

Two identical specimens in each condition were cold rolled together as a sandwich to $70 \%$ reduction. Possible effects of friction and roll contact were eliminated by using only the 'buttered' sides of the sandwich for subsequent measurement.

Annealing treatments were selected which would permit dissolution of the finely spaced carbides in sample FC without significantly 
modifying the overall carbon profile (minimal long range carbon diffusion). Following these treatments, measurements of texture and quantitative metallography were carried out at different depths below the surface corresponding to different known carbon contents. Textures were evaluated using the inverse pole figure method and orientation distribution functions (ODFs) according to the series expansion method. Quantitative metallography involved point counting and linear intercept methods using optical micrographs.

\section{RESULTS}

\subsection{Rolling textures}

After cold rolling the texture was almost constant and independent of the amount of carbon present or its state of dispersion. Figure 2(a) and (b) shows many of the important bcc texture components
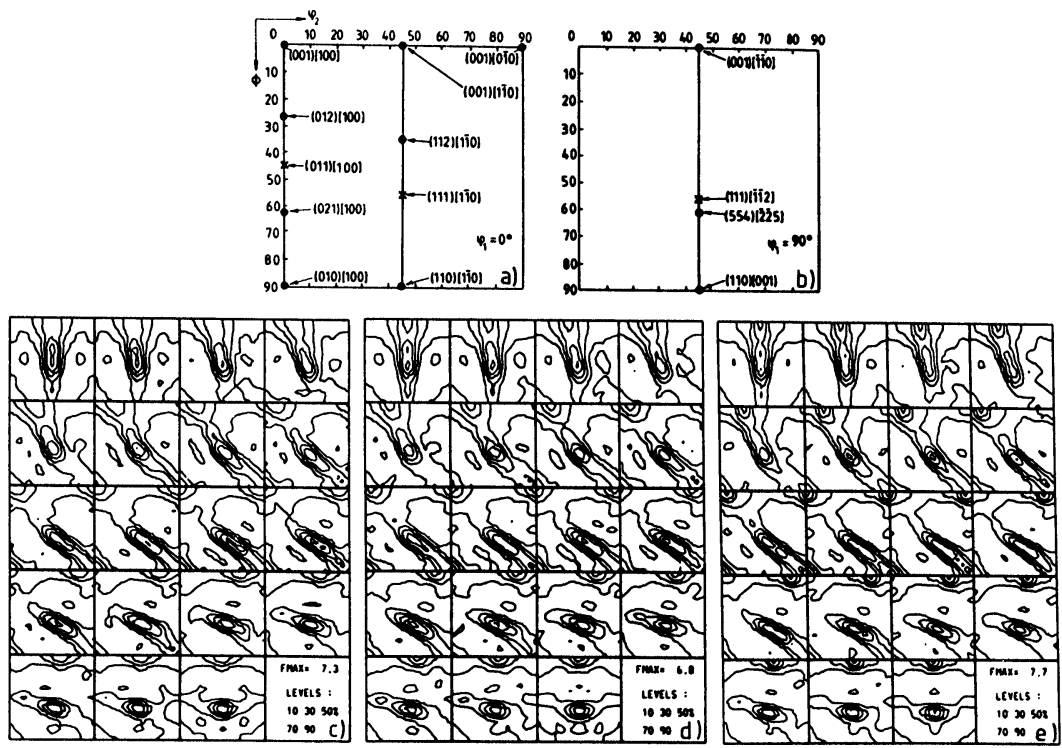

FIGURE 2 Orientation distribution plots showing (a) and (b) some principle orientations, (c), (d) and (e) cold rolled somples with (c) $150 \mathrm{ppm}$ carbon as grain boundary carbides, (d) $150 \mathrm{ppm}$ carbon in solid solution, and (e) $5 \mathrm{ppm}$ carbon prior to rolling. 
in two sections of orientation space. Figures 2(c)-(e) show sections for three measured rolling textures. These are the familiar $\langle 111\rangle / / \mathrm{ND}$ fibre and partial $\langle 110\rangle / / \mathrm{RD}$ fibre textures. The sample with the largest content of solid solution carbon has a slightly weaker texture than the others but the difference is almost within the limit of experimental uncertainty.

\subsection{Annealing textures}

Figure 3 shows the variation of the $\{111\},\{100\}$ and $\{110\}$ intensities as functions of carbon content after annealing at $700^{\circ} \mathrm{C}$ with a heating rate of $8 \mathrm{deg} . \mathrm{C} / \mathrm{s}$. Both WQ and FC materials showed maximum $\{111\}$ and minimum $\{100\}$ intensities at approximately $13 \mathrm{ppm}$ carbon. Increasing carbon content led to reduction in $\{111\}$ intensity which was especially marked for WQ

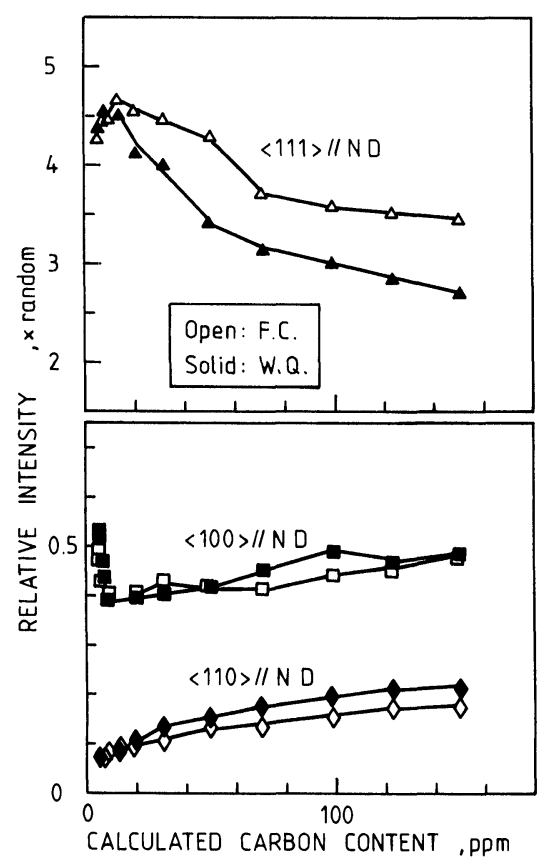

FIGURE 3 Inverse pole figure measurements as a function of carbon content for samples annealed to $700^{\circ} \mathrm{C}$. 
samples in which the carbon was in solid solution prior to cold rolling. The $\{110\}$ intensities increased over the same range. Below about $13 \mathrm{ppm}$ carbon the FC and WQ conditions were indistinguishable and showed a sharply reversed trend to lower $\{111\}$ values and higher $\{100\}$. Okamoto et al. ${ }^{11}$ previously observed a similar peak in the $\{111\} /\{100\}$ texture ratio for a carbon content of $\sim 3 \mathrm{ppm}$ under conditions of slow heating during annealing. The present authors have shown ${ }^{14}$ that the optimum carbon content shifts to higher values with increasing heating rate.

More detailed investigation of annealing textures using the ODF method were carried out for specimens isothermally annealed at $650^{\circ} \mathrm{C}$ for 5 minutes. Resulting ODFs are shown in Figure 4 and a selection of specific orientations are plotted out in Figure 5 as a function of carbon content. It can be seen that $\{111\}\langle 110\rangle$ decreased continuously and that $\{111\}\langle 112\rangle$ passed through a maximum with increasing carbon content. These components were weaker when carbon was in solid solution prior to cold rolling than when it was precipitated as fine carbides. The Goss component, $\{110\}\langle 001\rangle$ developed prominently in WQ samples containing more than about $50 \mathrm{ppm}$ dissolved carbon. A variety of minor components such as $\{100\}\langle 011\rangle,\{311\}\langle 011\rangle$ and $\{520\}\langle 001\rangle$ also developed with higher carbon contents for both WQ and FC series.

\subsection{Quantitative metallography}

Kinetic analyses of recrystallisation were carried out for samples isothermally annealed at $600^{\circ} \mathrm{C}$ and $650^{\circ} \mathrm{C}$. At higher temperatures the transformation occurred too quickly for experimental control. Low temperature investigations were omitted because of the danger that long range diffusion would modify the carbon cencentration profile through the sheet. Examples of some partially recrystallised structures are shown in Figure 6.

Measurements of fraction recrystallised, Figure 7, clearly show that the higher carbon contents cause acceleration of recrystallisation, especially in the WQ condition. For the lowest carbon centents ( 5 and $10 \mathrm{ppm}$ ) there was no detectable difference between FC and WQ conditions so the values have been averaged.

In order to learn more about the differences in recrystallisation kinetics, further measurements were made to separate the effects of 

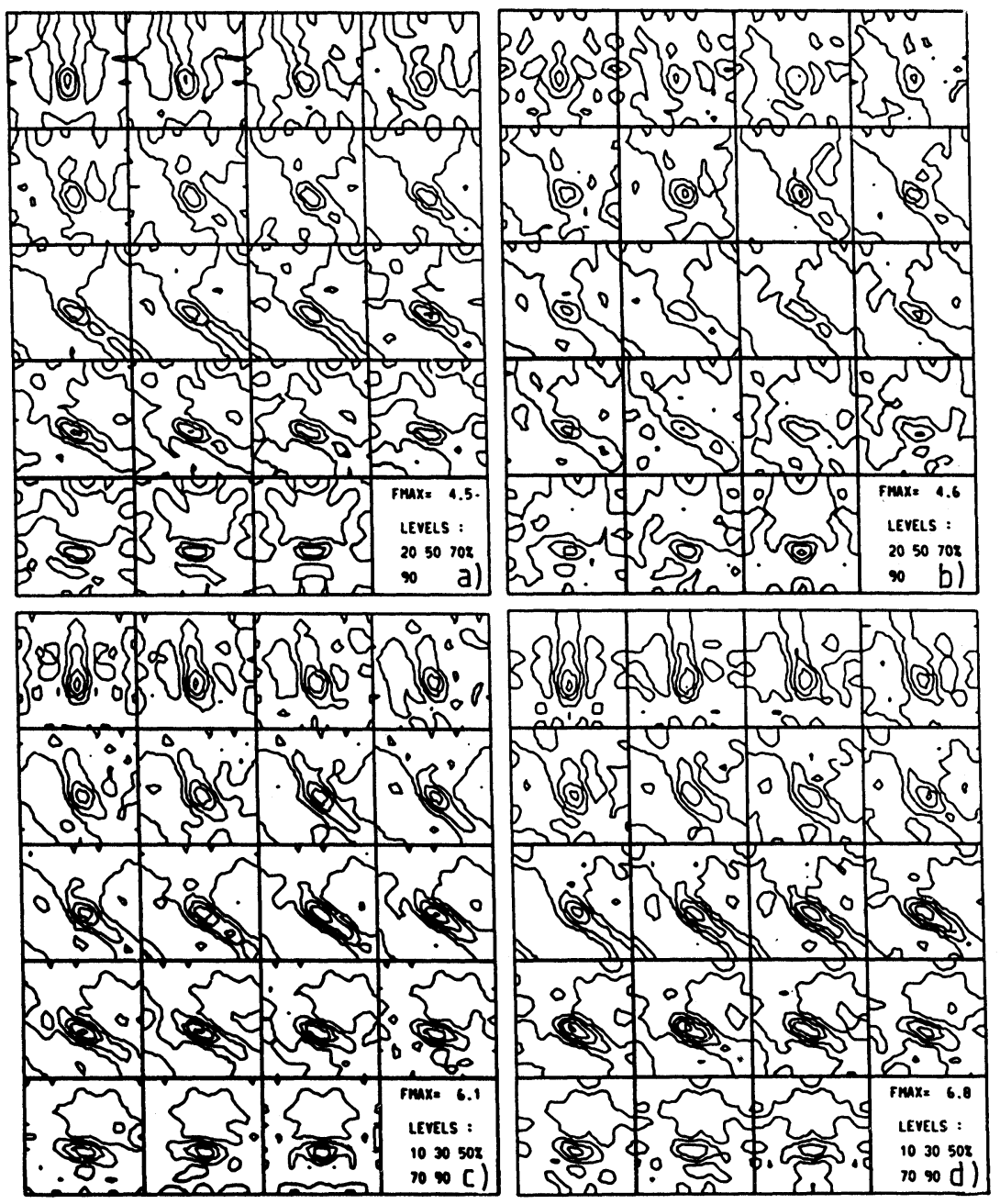

FIGURE 4 ODFs of cold rolled and isothermally annealed $\left(650^{\circ} \mathrm{C}-5 \mathrm{~min}\right)$ sheets a) $150 \mathrm{ppm}$ carbon in the form of grain boundary cementite, b) $150 \mathrm{ppm}$ carbon in solid solution, c) $30 \mathrm{ppm}$ carbon in solid solution, d) $5 \mathrm{ppm}$ carbon prior to cold rolling. 


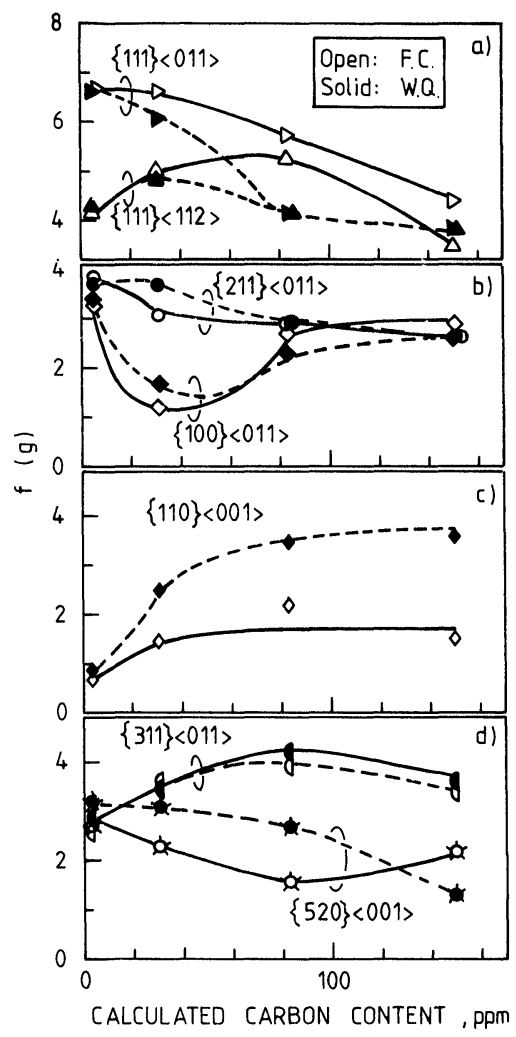

FIGURE 5 Variation of orientation density with carbon content for some selected texture components in sheets isothermally annealed at $650^{\circ} \mathrm{C}$ for 5 minutes.

nucleation and growth. Figure 8 shows measurements of the number of new grains per unit area for different stages of recrystallisation and different carbon contents. The number density of recrystallised grains increased markedly as the carbon content increased. Towards the end of the transformation there was frequently a decrease in number density due to competitive grain growth within the colonies of new grains. The effect of grain growth was most evident in cases where the average grain size was smallest and accordingly the driving force was greatest (high carbon content). 


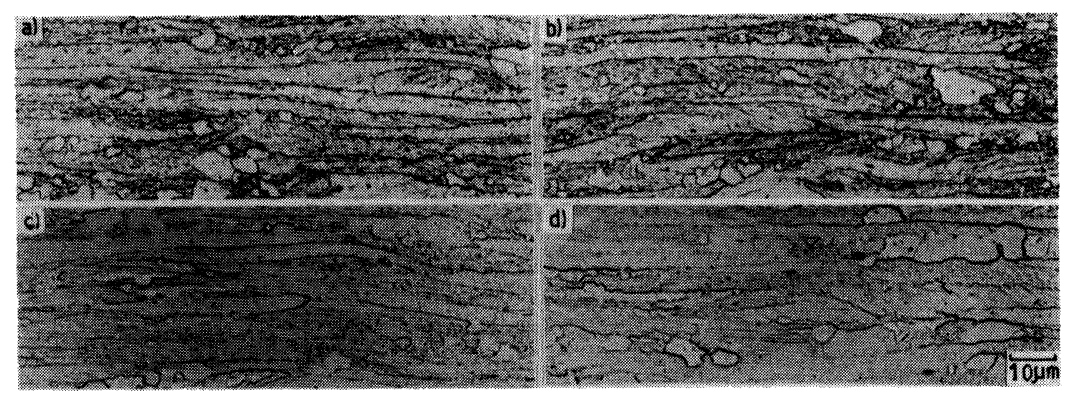

FIGURE 6 Optical micrographs showing the effect of carbon on the characteristics of recrystallisation: a) after annealing for $40 \mathrm{~s}$ at $600^{\circ} \mathrm{C}(f=0.28)$ for specimen $\mathrm{FC}$ having $85 \mathrm{ppm}$ carbon, b) after annealing for $30 \mathrm{~s}$ at $600^{\circ} \mathrm{C}(f=0.28)$ for specimen WQ having $85 \mathrm{ppm}$ carbon in solid solution, c) and d) are after annealing for $40 \mathrm{~s}$ $(f=0.08)$ and $50 \mathrm{~s}(f=0.28)$ at $600^{\circ} \mathrm{C}$, respectively for specimen with $5 \mathrm{ppm}$ carbon.

On the basis of the measurements in Figure 8 and the known annealing times it was possible to evaluate values for the apparent nucleation rate at various stages in the recrystallisation process. Figure 9 shows values of the nucleation rate calculated at $20 \%$ recrystallisation, a stage where the measurements were statistically reliable and still unaffected by competitive grain growth phenomena. It can be seen that the nucleation rate increased with carbon

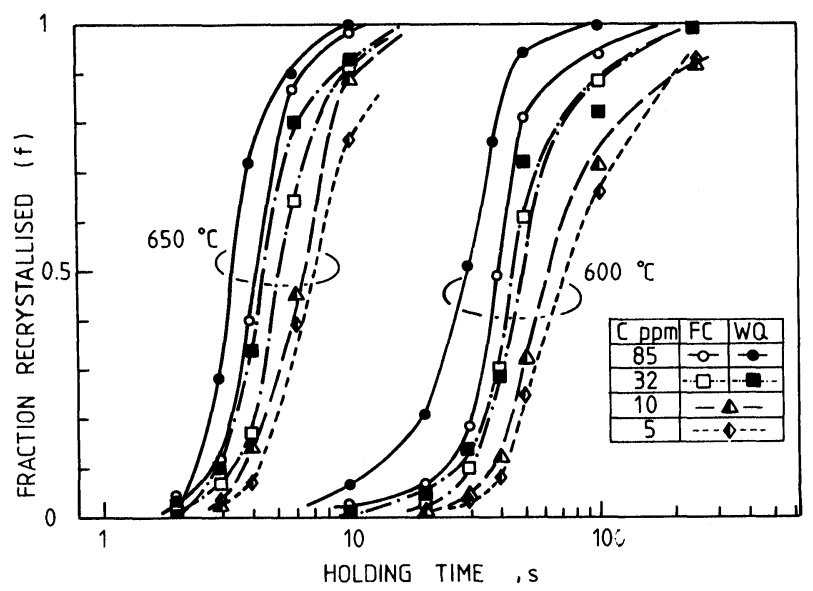

FIGURE 7 The change of fraction recrystallised with time during isothermal heat-treatment at $600^{\circ} \mathrm{C}$ and $650^{\circ} \mathrm{C}$. 


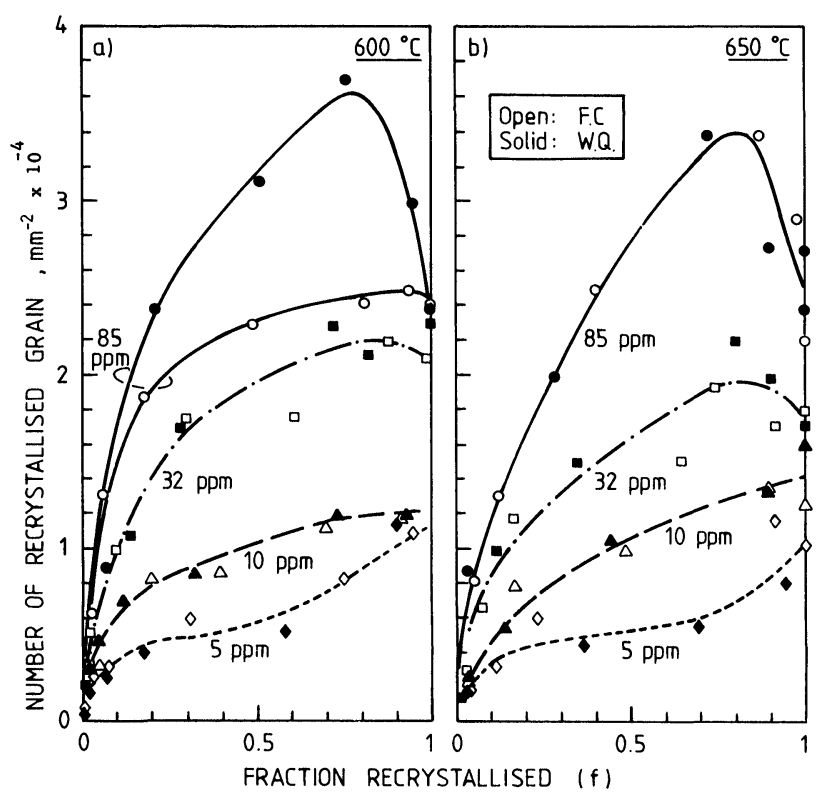

FIGURE 8 The change in number of recrystallised grains with fraction recrystallised during isothermal heat-treatment at $600^{\circ} \mathrm{C} 650^{\circ} \mathrm{C}$.

content, especially in the range $5 \mathrm{ppm}$ to $30 \mathrm{ppm}$. With still higher carbon contents there was a more modest increase in the nucleation rate. Condition WQ produced a somewhat higher rate than FC. The data in Figure 9 are only apparent nucleation rates in the sense that they refer to the number of grains which appear on the surface of section. A more meaningful value would be the rate of nuclei formation per unit volume of the steel. Although this has not been determined in the present study, it is known that the probability of a grain intersecting the surface is proportional to its diameter and so smaller grains (in the higher carbon cases) must be numerically less represented. This implies that the nucleation rate trend seen in Figure 9 would become further accentuated when expressed on a volume basis.

Growth rates of recrystallised grains have been measured using two different procedures. Firstly, the diameters of the largest unimpinged recrystallised grains were plotted against annealing time 
22 K. USHIODA, U. v. SCHLIPPENBACH AND W. B. HUTCHINSON

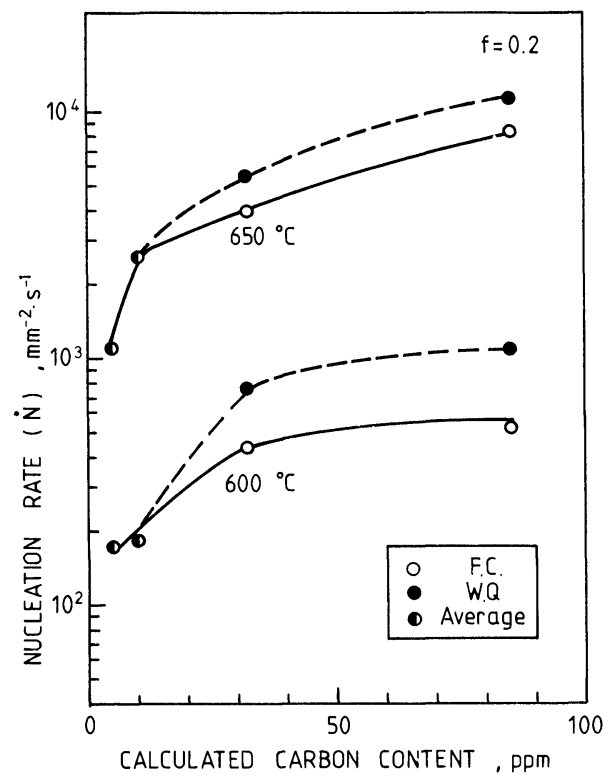

FIGURE 9 The variation of apparent nucleation rate with carbon content when fraction recrystallised, $f$, is 0.2 .

where the gradient of the resulting line is equal to twice the linear growth rate. These values correspond to the fastest possible growth and have been denoted as $G_{\max }$. In Figure 10 it can be seen that the $G_{\max }$ values were essentially constant at a given temperature, independent of the amount or distribution of carbon in the steel. A second alternative method was used following the description of Speich and Fisher. ${ }^{15}$ This method relies on the fact that the rate of recrystallisation $\left(\frac{d f}{d t}\right)$ is the product of surface area free to grow, $A$, (the boundary area recrystallised/unrecrystallised per unit volume) and the linear growth rate $(G)$. Thus

$$
\frac{d t}{d t}=A \cdot G
$$

where $G$ is now an average growth rate over all migrating fronts and 


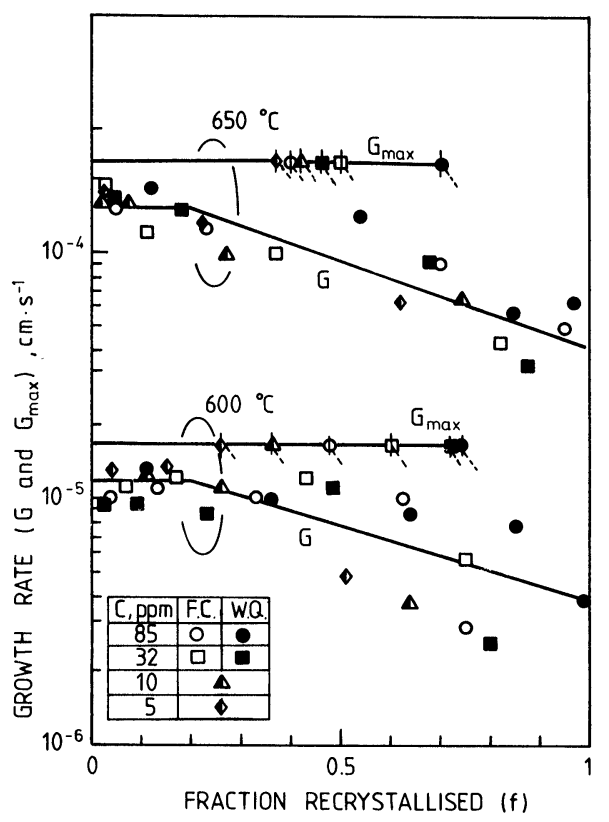

FIGURE 10 Measured growth rates for recrystallised grains at $600^{\circ} \mathrm{C}$ and $650^{\circ} \mathrm{C}$ for samples with four different total carbon contents.

$\frac{d f}{d t}$ is determined from the data in Figure 7. The area fraction, $A$, was measured by the standard linear intercept method and these results are presented in Figure 11 . Here it can be seen that $A$ increases quite markedly with carbon content which is another indication of the reduction in average grain size. Growth rate values calculated by the procedure are also shown in Figure 10. They lie below the $G_{\max }$ values as would be expected and show considerable scatter. However, there is no obvious indication that the values are affected by carbon content here. The average growth rate values tend to decrease when the fraction recrystallised exceeds about $20 \%$. This may be a result of concurrent recovery but is more probably associated with the spectrum of stored energy levels existing in the as-deformed material. Grains with high stored energy (notably $\{111\}$ oriented) are consumed first followed by grains of 


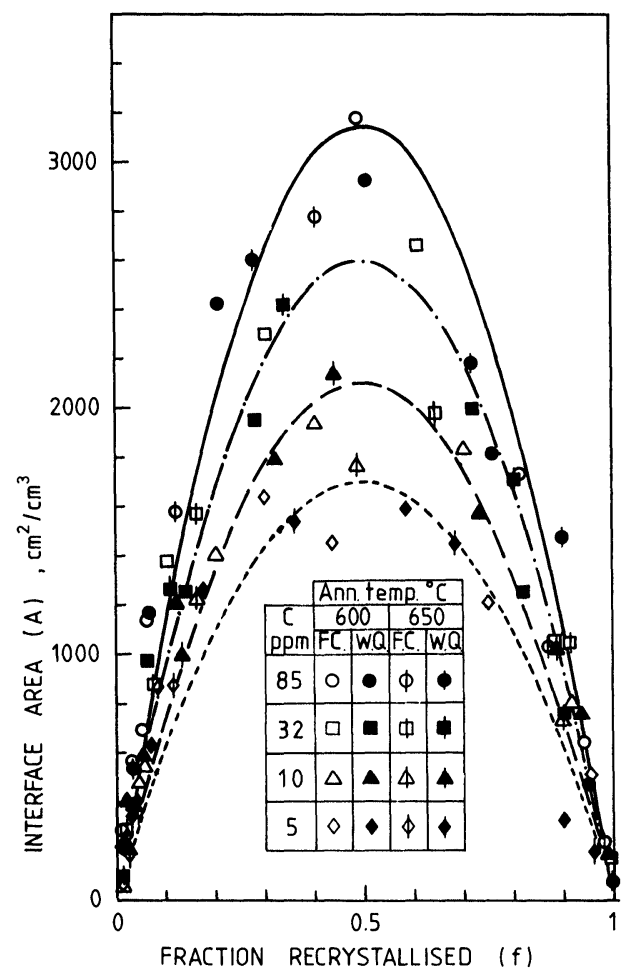

FIGURE 11 The variation of interface area between recrystallised and deformed regions with fraction recrystallised during isothermal heat-treatment.

lower stored energy (e.g. $\{100\}$ ) which provide correspondingly lower driving forces for growth. A summary of growth rate data at the stage where $20 \%$ of the structure has recrystallised is shown in Figure 12 . The values are remarkably constant, with just a slight increase for samples containing a high level of carbon in solid solution prior to cold rolling.

\section{DISCUSSION}

The present results obtained with the carbon gradient specimens agree well with observations of textures using more conventional 


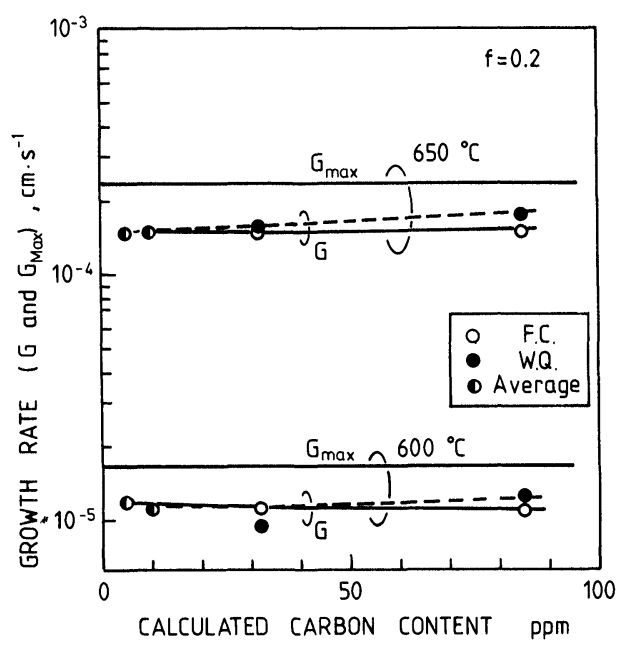

FIGURE 12 The variation of growth rate $\left(G\right.$ and $\left.G_{\max }\right)$ with carbon content when fraction recrystallised, $f$, is 0.2 for isothermal annealing at $600^{\circ} \mathrm{C}$ and $650^{\circ} \mathrm{C}$.

experimental methods. ${ }^{11}$ The main observations may be summarised as

i) very low carbon levels $(<\sim 13 \mathrm{ppm})$ increase the $\{100\}$ components and somewhat weaken $\{111\}$

ii) higher carbon contents decrease the $\{111\}$ components when present in solution during annealing (case FC) and have a generally randomising effect on the texture

iii) high contents of carbon in solution during rolling further depress the $\{111\}$ components and specifically favour the Goss component after recrystallisation.

The microstructural studies in the present work show that there are in some cases changes in the pattern of recrystallisation which are probably responsible for the differences in texture development. An exception appears to be the behaviour at very low carbon levels, (i) above, which does not obviously correlate with any change in recrystallisation kinetics.

The effect of carbon in solution during annealing, (ii) above, is especially interesting because of its significance in the commercial 
processing of steel. The situation is complicated by the fact that manganese must also be present in solid solution in order for the carbon to excercise its deleterious effect. Ushioda and Hutchinson ${ }^{16}$ have shown that the simultaneous presence of dissolved carbon and manganese reduces the rate of recovery after cold rolling. Rather surprisingly, it is seen here that the nucleation rate in recrystallisation increases under the same conditions. It might be argued that the enhancement of nucleation with increasing carbon in samples FC and the associated weakening of the annealing texture is caused by the particles themselves rather than the carbon which they liberate into the matrix. However, this seems unlikely for several reasons. Firstly, the carbides in the grain boundaries are much less than $1 \mu \mathrm{m}$ thick and so are below the size at which particlestimulated nucleation is believed to occur. Secondly, the change in nucleation rate does not mirror the change in particle density (Fig. 1) but occurs principally at lower carbon contents. Thirdly, there are other independent observations demonstrating the effect of dissolved carbon (e.g. refs $7,11,12$ ) which cannot be due to initiation of recrystallisation at particles.

A possible explanation of the role of dissolved carbon during annealing can be attributed to the action of $\mathrm{Mn}-\mathrm{C}$ complexes $^{17}$ inhibiting recovery. It is known ${ }^{18}$ that differences in stored energy exist after cold rolling as a function of grain orientation. These differences in stored energy provide a driving force for strain induced grain boundary migration (SIBM) which gives rise to nucleation from low stored energy regions such as $\{100\}$. Recovery would normally act to reduce differences in stored energy and so minimise nucleation by SIBM. It is possible that inhibition of recovery by $\mathrm{Mn}-\mathrm{C}$ complexes results in a higher nucleation rate due to a higher incidence of SIBM nucleation which would, at the same time, bring about a weakening of the final $\{111\}$ texture strength.

The situation with regard to observation (iii) is rather easier to explain. Steel with a high interstitial content is prone to dynamic strain ageing and shear banding during cold rolling. ${ }^{19}$ Shear bands form most readily in matrix grains of orientation $\{111\}\langle 112\rangle$ and these highly deformed sites lead to copious nucleation of recrystallisation during subsequent annealing. Some example of recrystallisation in shear bands are seen in Figure 6(b). The new 
grains which develop from these sites have strong preference for the Goss orientation at the expense of the $\{111\}$ orientations, which agrees well with the observed textures in the ODFs of high carbon WQ samples. Naturally, the carbon remains in solution during annealing and so further contributes to weakening of the $\{111\}$ texture as in the case of the FC samples. The further enhancement of nucleation rate in WQ samples as compared to FC can therefore be attributed to shear band nuclei. The small increase in growth rate for grains in high carbon WQ samples is considered to arise from the higher density of stored dislocations resulting from deformation under dynamic strain ageing conditions.

\section{CONCLUSIONS}

The use of samples having a controlled gradient of carbon is a sensitive and experimentally economic way to study the effect of different carbon contents in steel sheet.

The presence of carbon in solid solution (together with manganese) during annealing tends to randomise the final texture and weaken the $\{111\}$ components. This effect is associated with an increase in the nucleation rate of recrystallised grains for higher carbon contents, their rate of growth being essentially unchanged.

Carbon which is present in solid solution already prior to cold rolling gives rise to additional weakening of the $\{111\}$ texture and augments the Goss component. At the same time the nucleation rate for recrystallisation is further enhanced and the growth rate increases slightly. Dynamic strain ageing and associated shear banding are believed to be responsible for these changes in texture and recrystallisation kinetics.

\section{Acknowledgements}

Financial support and the provision of materials from Nippon Steel Corporation and Svenskt Stål AB are gratefully acknowledged. Thanks are also expressed to Prof K. Lücke for provision of the ODF facility. The activation analyses for carbon were carried out by courtesy of Dr. L. Earwaker of the University of Birmingham Radiation Centre, England. 


\section{References}

1. Hutchinson, W. B. (1984). Int. Met. Reviews 29, p. 25.

2. Takahashi, N., Abe, M., Akisue O. and Katoh, H. (1982). Proc. Conf. on Metallurgy of Continuous-Annealed Sheet Steel, AIME, Dallas, p. 51.

3. Obara, T. O., Satoh, S., Nishida N. and Irie, T. (1984). Scan. J. Metallurgy 13, 201.

4. Hu H. and Goodman, S. R. (1970). Met. Trans. 1, 3057.

5. Hughes I. F. and Page, E. W. (1971). Metall. Trans. 2, p. 2067.

6. Matsudo, K., Osawa, K., Suzuki, T. and Kurihara, K. (1984). Proc. 7th Int. Conf. on Textures of Materials, p. 643.

7. Hutchinson, W. B. and Ushioda, K. (1984). Proc. 7th Int. Conf. on Textures of Materials, p. 409.

8. Leslie, W. C., Plecity, F. J. and Michalak, J. T. (1961). Trans. Metall. Soc. AIME 221, p. 691.

9. Venturello, G., Antonione, C. and Bonaccoroso, F. (1963). Trans. Metall. Soc. AIME 227, p. 1433.

10. Antonione, C., Della Gatta, G. and Venturello, G. (1964). Trans. Metall. Soc. AIME 230, p. 700.

11. Okamoto, A. and Takahashi, M. (1981). Proc. 6th Int. Conf. on Textures of Materials, p. 739.

12. Ushioda, K., Hutchinson, W. B., Ågren, J. and Schlippenbach, U. v. (1986). Materials Science and Technology, 2, 807.

13. Simpson, J. C. B. and Earwaker, L. J. (1984). Vacuum 34, 899.

14. Ushioda, K., Agren, J. and Hutchinson, W. B. (1984). Proc. 7th Int. Conf. on Textures of Materials, p. 301.

15. Speich, G. R. and Fisher, R. M. (1986). Recrystallisation Grain Growth and Textures, $A S M$ p. 563.

16. Ushioda, K. and Hutchinson, W. B. Swedish Institute for Metals Research, unpublished work.

17. Abe, H. (1984). Scan. J. Metallurgy 13, 226.

18. Dillamore, I. L., Smith, C. J. E. and Watson, T. W. (1967). Metals Sci. J. 1, p. 49.

19. Ushioda, K., Ohsone, H. and Abe, M. (1981). 6th Int. Conf. on Textures of Materials, p. 829. 